UDC: $159.964 ; 944$

DOI: 10.26697/ijes.2019.2.38

\section{Archetypes as a Factor of Personality's Professionalization}

Postgraduate Student Tanasiychuk E. N. ${ }^{1}$

${ }^{1}$ Kherson State University, Ukraine

\begin{abstract}
Background:

Nowadays, it is crucial to be a specialist in the professional environment of the personality. However, as Panok notes several issues are connected with the professionalization of psychologists, namely: professional teacher training and the level of methodological training, the workload of teachers, the professional orientation of students as future specialists, the lack of a professional position. Among other ways of solving the issues, Panok considers the need for restructuring the educational system and the formation of professional orientation and professional status. The archetypological basis for professional training and professional development plays a decisive role and allows forming the necessary professional qualities at the beginning of the professional path by updating the basic archetypal behavioral and emotional patterns, or will enable first-year students to realize the motivation of their choice that does not correspond to the professional orientation.
\end{abstract}

\footnotetext{
Results:

Ideas about archetype determination are only emerging and have different variations in psychological works. In his works, Hillman clearly showed the influence of archetypes on the personality in general and the professional development in particular. Thus, the primacy of images means that they are presented in the field of knowledge, the instinctive activity of which is carried out at the volitional level. In the area of the conscious mind, instinct is perceived in a symbolic form. In the field of behavior, images are manifested in instinct. The energy of the archetype is instinctive since the archetype is a behavioral pattern of instinct, its meaning or its mental equivalent. The mental structure is a dramatic process, and based on this personality is a theater of archetypal figures, which can vary and complement each other in the process of professionalization.

Jung defines instinct as the attraction for a certain activity, which is urgent and insurmountable, inherited, reflexive in its character, invariable, regular and unconscious. It is an archetype which guides the psychic life of the individual. Jung specified that the real is perceived and analyzed by the psyche; collective is a common one, which provides communication of people on the same level, including in professional activity. Archetypes affect not only the internal state of the personality but are also shown in the external reality; they are both objective and subjective, which means that the professional development depends on the development of the personality archetype.
}

In works by Neumann, one can also find a description of the archetypal influence on personality. The archetype is represented by a model consisting of symbolic, dynamic, and sensory components. Symbolism means the manifestation of an archetype in consciousness in the form of an image; dynamism is the influence of archetype on the mental organization of personality and its activity with different emotional states; sensuality is revealed through the material component perceived by the consciousness provided assimilation of the unconscious content of the archetype. According to the author, the archetype can be conscious or remain in the unconscious, and affect the propensity, interests, and intentions of the personality.

Druzhinina defends the position of dynamism of the world and introduces the concept of an actual archetype, which is understood by the archetypal image associated with the realization of reality and allows adapting to the modern world, including the professional one.

More recent studies point to the close connection between the profession of psychologist and its archetype beginning. Thus, Dotsenko and Borko note that psychologists, as carriers of household consciousness, are partly associated with the myths that form the basis for professional activity.

According to Bratus, psychology as a whole has a strong potential of myth-making and mythtransformation, which significantly influences professional activity. Zarubko notes the need to study the archetypal elements in the professional consciousness of personality.

\section{Conclusions:}

The professionalization of personality is an integral part of human life. The study of the archetype basis for the professional formation will provide an opportunity for timely professional orientation at the stage of professional direction.

\section{Information about the author: Tanasiychuk Elena Nikolaevna - Postgraduate Student, Kherson State University, Kherson, Ukraine. Research interests: gender psychology, family psychology, group methods of psychological work.}

Corresponding Author:

Tanasiychuk Elena Nikolaevna

Corresponding Author's Email:

prioralaunch@gmail.com 